\title{
Occupational contamination with americium and Ca-DTPA treatment
}

\author{
D. PELCLOVÁ 1 , Z. FENCLOVÁ
}

(Manuscript received 5 April 2004, accepted 29 April 2004)

ABSTRACT Dismantling and decommissioning operation of three glove boxes contaminated by ${ }^{241} \mathrm{Am}$ was conducted in summer 2001. During the first two terms of the decommissioning project no hesitation appeared about the adequacy of the protective regime. After measuring of filters from ventilation during the third term the volume activity was assessed as $1.5 \mathrm{~Bq} / \mathrm{m}^{3}$ with the volume of filtered air of $69.2 \mathrm{~m}^{3}$ at a flow rate of $1 \mathrm{~m}^{3}$ per hour and all the working activities were stopped. On the basis of first results, six workers were treated with calcium trisodium diethylene-triamine-pentaacetate (Ca-DTPA) in infusions. The check of urine proved the increased excretion of contaminating radionuclide. The tolerance of the treatment was good. Final evaluation based on complex excretion data in the workers pointed to the committed effective dose of 35-185 mSv. This extraordinary event was caused first of all by the considerable underestimation of the hazard of the dismantling of dry glove boxes.

RÉSUMÉ Contamination professionnelle par de l'américium et traitement par le Ca-DTPA.

Le déclassement et le démantèlement de trois boîtes à gants contaminées par de l'américium 241 ont été conduits durant l'été 2001. Pendant les deux premières phases du projet de déclassement aucune hésitation n'est apparue sur l'adéquation du système de protection. La mesure des filtres de la ventilation durant la troisième étape a donné une activité volumique de $1,5 \mathrm{~Bq} / \mathrm{m}^{3}$ pour un volume d'air filtré de $69,2 \mathrm{~m}^{3}$ au débit de $1 \mathrm{~m}^{3}$ par heure, ce qui a entrainé l'arrêt des opérations. Sur la base des premiers résultats, six travailleurs furent traités par perfusion de CaDTPA. Le contrôle des urines a montré une augmentation de l'élimination du radionucléide contaminant. La tolérance au traitement fut bonne. L'évaluation finale basée sur les données complexes d'excrétion a conduit à estimer la dose effective engagée entre 35 et $185 \mathrm{mSv}$. Cet évènement anormal a été causé tout d'abord par la grande sous-estimation du risque.

During June and July 2001 a dismantling and decommissioning operation of three glove boxes in which radionuclides had been handled for a long time was conducted in the Nuclear Research Institute near Prague. These glove boxes served before in another plant as a part of line for producing ${ }^{241} \mathrm{Am}$ sources for smoke detectors. The basic material was always americium oxide, which was for some purposes chemically treated and used as americium nitrate. The dismounting

\footnotetext{
1 Centre of Specialised Health Care for Persons after Radiation Accidents, Department of Occupational Medicine. Ist Medical Faculty, Charles University, Na Bojišti 1, 12000 Prague, Czech Republic.
} 
procedure took place in three time periods, the data of critical operations being June 21st, July 3 rd and July 10th. In the course of dismounting project aerosol particles with ${ }^{241} \mathrm{Am}$ were incidentally released and due to violation of some radiation protection regulations several workers were internally contaminated. The manufacturing company declared at the time of transfer the activities in glove boxes prepared for waste process as $150 \mathrm{MBq}, 180 \mathrm{MBq}$ and $50 \mathrm{MBq}$ of ${ }^{241} \mathrm{Am}$, respectively. Before the transport, the contamination on the walls and on the inside installation was fixed by lacquer. After the removal of the covering foil, opening the box and it's dismounting the material was fragmented and put into steel drums and conditioned by cementing.

During the first two terms of the decommissioning project no hesitation appeared about the adequacy of the protective regime and its full efficiency. The local ventilation and the exhausters from the working area were in operation and the workers used the usual protective aids including respirators. The feeling of safety proved, however, false as a result of neglected rules of area and personnel monitoring. The measuring of filters from ventilation system covering the period of the two first operations was finished and the results reported to the responsible supervisor only after the third operation had been over. As a result, the third wasteprocessing task on July 10 th was performed without any warning about possible extraordinary conditions. The volume activity was assessed as $1.5 \mathrm{~Bq} / \mathrm{m}^{3}$ (so-called $\alpha$ activity) with the volume of filtered air of $69.2 \mathrm{~m}^{3}$ at a flow rate of $1 \mathrm{~m}^{3}$ per hour. The supervisor ordered to stop all the working activities in the working area on July 10 th at 12.30 .

The next day the results from the filter covering the operations performed on July 10th were presented: the mean activity $13.10 \mathrm{~Bq} / \mathrm{m}^{3}(\alpha)$ was found with the volume of filtered air of $5.6 \mathrm{~m}^{3}$. The same day the measurement of respirators used by workers revealed a considerable contamination, reaching in the worst case to $2700 \mathrm{~Bq}$. The chief of the department evaluated the situation as an increase of volume activity above the derived investigation level, declared at 16.30 an extraordinary event of the grade I in the terms of national regulations and notified this to the State Office for Nuclear Safety (SONS).

First worker who was wearing the respirator on which the highest activity was found was directed to the National Radiation Protection Institute (NRPI) for detailed measurements. On July 12 th the first in vivo investigation was performed in this worker and results were reported to SONS. From the first two in vivo measurements the body burden of ${ }^{241} \mathrm{Am}$ was estimated at about $5 \mathrm{kBq}$ and considering the date July 10 th as the time of intake, the committed effective dose (E 50) was assessed in the order of sieverts. The evaluation was based on the presumption that inhalation of particles of aerodynamic median activity diameter 
TABLE I

Estimation of the DTPA administration efficiency according to Malátová et al. (2003). Estimation de l'efficacité du traitement par le DTPA selon Malátová et al. (2003).

\begin{tabular}{|c|c|c|c|c|c|c|}
\hline Worker & M & 2 & 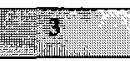 & $4=$ & 5 & 6 \\
\hline Before DTPA $[\mathrm{Bq} / \mathrm{d}]$ & 0.085 & 0.004 & 0.04 & 0.050 & - & - \\
\hline Days of sampling & 2 & 2 & 3 & 3 & - & - \\
\hline After DTPA [Bq/d] & 0.52 & 0.055 & 0.53 & 0.096 & 0.89 & 0.99 \\
\hline Days of sampling & 4 & 4 & 4 & 3 & 3 & 3 \\
\hline Longer time after DTPA admin. [Bq/d] & 0.135 & - & - & - & 0.13 & 0.48 \\
\hline Days of sampling & 8 & - & . & - & 3 & 3 \\
\hline Excess of excreted activity $|\mathrm{Bq}|$ & 1.6 & 0.22 & 1.9 & 0.14 & 2.3 & 3.0 \\
\hline
\end{tabular}

(AMAD) $5 \mu \mathrm{m}$, class $\mathrm{M}$, was the main mechanism of internal contamination. It was, however, recognized that these figures could be overestimated due to the contamination, which remained on the body surface in spite of thorough showering before measurements and absence of positive response of surface monitors $(\alpha)$. Later it was shown from the measurements of a pillow from the department of occupational medicine and from a specimen of hair from a haircut that some contamination indeed adhered to the scalp. In the meantime, the collection of stool and urine was started. The repeated in vivo investigations (whole body counting, head and knees) and evaluation of the first excreta results enabled soon to decrease the initial estimates, so that the committed effective dose was quantified as $350 \mathrm{mSv}$. On July 17th it was decided to report the event to the IAEA in Vienna. The tentative classification pointed to the level of International Nuclear Event Scale (INES) 2 (INES, 2001). Whole body counting, measurement of head and of knee were conducted, measurable contamination was found in seven workers and their further follow-up was organised.

On the basis of first results, six workers were treated at the Centre of Specialised Health Care for Persons after Radiation Accidents of the Department for Occupational Medicine (Fenclová et al., 2000) with calcium trisodium diethylene-triamine-pentaacetate (Ca-DTPA) in 4-hours infusions of $1 \mathrm{~g}$ of CaDTPA in saline solution. One worker was hospitalised at our department from July 13th and was treated with two doses of Ca-DTPA (on July 14th and 17th), five more workers were hospitalised from July 20th and were given also two doses of Ca-DTPA (on July 20th and 22nd). The check of urine proved the expected response in the terms of increased excretion of contaminating radionuclide. The excretion in Bq/day before and after DTPA treatment is shown in Table I, more details brought Malátová et al., who performed the measurements (Malátová et al., 
2003). The tolerance of the treatment was good, no adverse effects were observed, except minor increase of zinc and copper excretion in urine and very mild decrease of zinc level in blood. Mean blood and urine concentrations of sodium, potassium, chlorine, calcium, phosphorus and magnesium both before and after the treatment were within the normal range.

After the assessment of the intakes had been amended, no continuation of the treatment seemed to be justified. The decrease of the in vivo results below detection limits during weeks confirmed the interference of early findings with surface contamination. A final evaluation in January 2002 was based on excretion data and pointed to the committed effective dose (E50) in the range of 35-185 mSv. The excretion analysis suggested, that in some workers repeated intakes might occur, partly already on June 21 st and July 3rd (during the first two operations) or especially after July 10th during cleaning of the area. This uncertainty complicated the interpretation of excretion results (Malátová et al., 2003). Also, the parameters of the contaminant are not known, AMAD of particles, its chemical composition. It is possible, that the physical and chemical parameters were influenced by fixating lacquer used against the spread of contamination during dismounting of hermetic boxes.

The inspection of SONS concluded that this extraordinary event was caused first of all by the considerable underestimation of the hazard of the dismantling and fragmentation of dry glove boxes contaminated by ${ }^{241} \mathrm{Am}$. Some important elements of the periodic safety control were lacking including a thorough ad regular documentation of all indices and circumstances important for protection. Personal clothing and protective aids including respirators were not checked daily and were not changed as frequently as appropriate. The working task should have been prepared in more detail.

An interesting comparison of the results of personal air samplers and stationary air samplers was performed during a plutonium glove box decommissioning project and recently published (Munyon and Lee, 2002). The influence of room geometry and ventilation rate on aifflow and aerosol dispersion should always be taken into account in modelling of working conditions (Whicker et al., 2002).

It remains to consider the environmental impact of this accident. The filters in the outlet of the air from the Fragmentation and Decontamination Centre building to the stack of the facility detected measurable activity of ${ }^{241} \mathrm{Am}$ released during dismantling operations. Quantitative evaluation of measurements showed that this release might result in a maximum individual $\mathrm{E} 50$ of $3.5 \mu \mathrm{Sv} / 50$ years in a circular area with $400 \mathrm{~m}$ radius area around the laboratory. This estimate does not exceed the criteria of INES 1, derived from the release of ${ }^{106} \mathrm{Ru}$ as the reference nuclide. 
Still the final position of SONS is to keep on the initial conservative classification of INES 2 because the estimated E50 exceeded at least in one radiation worker the level of annual dose limit.

Acknowledgement. During the course of event the clinical group contacted several international experts to consult the details of medical handling of contaminated workers. The officers of IAEA mediated readily some useful information exchange. The authors appreciate prompt answers of Dr. Nogueira de Oliveira, Dr. Strandberg, Dr. Breitenstein, Dr. Métivier, Dr. Fliedner, Dr. Ricks, Dr. Stradling, Dr. Goans, Dr. Souchkevitch, Dr. Cosset, Dr. Kontchaklovsky, Dr. Frolov, and Dr. Gousev. More co-workers from the institutions participating on the handling of this accident i.e. from Nuclear Research Institute in $\check{R} e \bar{z}$, National Radiation Protection Institute, Department of Occupational Medicine, Ist Medical Faculty Charles University, and State Office for Nuclear Safety contributed substantially to the collecting and evaluating the appropriate data. Their engagement in this work is deeply acknowledged. Work on this manuscript was supported by MSM 111100002 and MSM 111100005.

\section{REFERENCES}

Fenclová Z., Pelclová D., Klener V., Lebedová J. (2000) Medical preparedness for radiological accidents in the Czech Republic and selected case reports of radiation victims treated at the Prague Health Center, Centr. Eur. J. Occup. Environ. Med. 6, 257-264.

INES (2001) The International Nuclear Event Scale, User's Manual, IAEA and OECD/NEA, Vienna.

Malátová I., Bečková V., Pospîšilová H. (2003) Internal contamination with ${ }^{241}$ Am during handling of radioactive waste, IRPA Regional Congress on Radiation Protection in Central Europe, September 22-26, Bratislava, Slovakia, Proceedings on CD Rom, ISBN 80-88806-43-7.

Munyon W.J., Lee M.N. (2002) Summary of stationary and personal air sampling measurements made during a plutonium glove box decommissioning project, Health Phys. 82, 244-253.

Whicker J.J., Wasiolek P.T., Tavani R.A. (2002) Influence of room geometry and ventilation rate on airflow and aerosol dispersion: implications for worker protection, Health Phys. 82, 52-63. 